\title{
Recommendations for Improving Consistency in the Radiation Fields Used During Testing of Radiation Detection Instruments for Homeland Security Applications
}

\author{
L. Pibida ${ }^{1}$, M. Mille ${ }^{1,2}$, and B. Norman ${ }^{1}$ \\ ${ }^{1}$ National Institute of Standards and Technology, \\ Gaithersburg, MD 20899 \\ ${ }^{2}$ Nuclear Engineering and Engineering Physics Program, \\ Rensselaer Polytechnic Institute, \\ Troy, NY 12180 \\ leticia.pibida@nist.gov \\ matthew.mille@nist.gov \\ bruce.norman@nist.gov
}

Several measurements and calculations were performed to illustrate the differences that can be observed in the determination of exposure rate or ambient dose equivalent rate used for testing radiation detection systems against consensus standards. The large variations observed support our recommendation that better consistency in the test radiation fields can be achieved by specifying the source activity and testing distance instead of the field strength.

Key words: ANSI/IEEE standards testing; exposure rate constants; radiation field determination; source activity.

Accepted: May 7, 2013

Published: May 28, 2013

http://dx.doi.org/10.6028/jres.118.014

\section{Introduction}

Commercially available radiation detection instruments for homeland security applications are currently being tested against American National Standard Institute/Institute of Electrical and Electronics Engineers (ANSI/IEEE) and International Electrotechnical Commission (IEC) standards. Table 1 lists the relevant ANSI/IEEE and IEC standards which have been published or are currently under development. These standards cover a wide variety of instruments from small personal radiation detectors (PRDs) to large radiation portal monitors (RPMs). The chief function of these detectors is to measure the magnitude of the radiation field (often expressed as exposure rate or ambient dose equivalent rate), and not to provide a dose record to the user. In fact, some of the instruments only report the radiation field in units of counts per second. 
Table 1. List of published ANSI/IEEE and IEC standards

\begin{tabular}{|c|c|}
\hline ANSI/IEEE standards & IEC standards \\
\hline $\begin{array}{l}\text { ANSI/IEEE N42.32 } \\
\text { Performance Criteria for Alarming Personal Radiation } \\
\text { Detectors for Homeland Security }\end{array}$ & $\begin{array}{l}\text { IEC } 62401 \\
\text { Radiation protection instrumentation - Alarming personal } \\
\text { radiation devices (PRD) for detection of illicit trafficking of } \\
\text { radioactive material }\end{array}$ \\
\hline $\begin{array}{l}\text { ANSI/IEEE N42.33 } \\
\text { Portable Radiation Detection Instrumentation for Homeland } \\
\text { Security }\end{array}$ & $\begin{array}{l}\text { IEC } 62533 \\
\text { Radiation protection instrumentation - Highly sensitive hand- } \\
\text { held instruments for photon detection of radioactive material }\end{array}$ \\
\hline $\begin{array}{l}\text { ANSI/IEEE N42.34 } \\
\text { Performance Criteria for Hand-held Instruments for the } \\
\text { Detection and Identification for Radionuclides }\end{array}$ & $\begin{array}{l}\text { IEC } 62327 \\
\text { Radiation protection instrumentation - Hand-held instruments for } \\
\text { the detection and identification of radionuclides and for the } \\
\text { indication of ambient dose equivalent rate from photon radiation }\end{array}$ \\
\hline $\begin{array}{l}\text { ANSI/IEEE N42.35 } \\
\text { Evaluation and Performance of Radiation Detection Portal } \\
\text { Monitors }\end{array}$ & $\begin{array}{l}\text { IEC } 62244 \\
\text { Radiation protection instrumentation - Installed radiation } \\
\text { monitors for the detection of radioactive and special nuclear } \\
\text { materials at national borders }\end{array}$ \\
\hline $\begin{array}{l}\text { ANSI/IEEE N42.38 } \\
\text { Performance Criteria for Spectroscopy-Based Portal Monitors } \\
\text { Used for Homeland Security }\end{array}$ & $\begin{array}{l}\text { IEC } 62484 \\
\text { Radiation protection instrumentation - Spectroscopy-based portal } \\
\text { monitors used for the detection and identification of illicit } \\
\text { trafficking of radioactive material }\end{array}$ \\
\hline $\begin{array}{l}\text { ANSI/IEEE N42.43 } \\
\text { Performance Criteria for Mobile and Transportable Radiation } \\
\text { Monitors Used for Homeland Security }\end{array}$ & $\begin{array}{l}\text { No IEC standard currently available for mobile and transportable } \\
\text { systems }\end{array}$ \\
\hline $\begin{array}{l}\text { ANSI/IEEE N42.48 } \\
\text { Performance Requirements for Spectroscopic Personal } \\
\text { Radiation Detectors (SPRDs) for Homeland Security }\end{array}$ & $\begin{array}{l}\text { IEC } 62618 \\
\text { Radiation protection instrumentation - Spectroscopy-based } \\
\text { alarming Personal Radiation Detectors (SPRD) for the detection } \\
\text { of illicit trafficking of radioactive material }\end{array}$ \\
\hline $\begin{array}{l}\text { ANSI/IEEE N42.53 } \\
\text { Performance Criteria for Backpack Based Radiation Detection } \\
\text { Systems Used for Homeland Security }\end{array}$ & $\begin{array}{l}\text { IEC } 62694 \\
\text { Radiation protection instrumentation - Backpack-type radiation } \\
\text { detector (BRD) for detection of illicit trafficking of radioactive } \\
\text { material }\end{array}$ \\
\hline $\begin{array}{l}\text { No ANSI/IEEE standard currently available for highly sensitive } \\
\text { neutron detectors }\end{array}$ & $\begin{array}{l}\text { IEC } 62534 \\
\text { Radiation protection instrumentation - Highly sensitive hand- } \\
\text { held instruments for neutron detection of radioactive material }\end{array}$ \\
\hline
\end{tabular}

Most of the standards in Table 1 place specific requirements on the strength of the radiation field used for testing, typically defining it at the reference point of the detector through a measure of exposure rate (expressed in $\mu \mathrm{R} / \mathrm{h})^{1}$ or ambient dose equivalent rate $\left(H^{*}(10)\right.$, expressed in units of $\left.\mu \mathrm{Sv} / \mathrm{h}\right)$. Several of the tests described in these standards require fields ranging from $5 \mu \mathrm{R} / \mathrm{h}$ to $50 \mu \mathrm{R} / \mathrm{h}$ above average background levels at the test location. Yet, the background radiation for testing laboratories within the United States can range from $5 \mu \mathrm{R} / \mathrm{h}$ to $25 \mu \mathrm{R} / \mathrm{h}$ depending on the geographic location. This means that laboratories performing testing against these standards are required to determine the testing radiation field very close to or even below background radiation levels. This poses a challenge in the method used to determine the testing radiation field. Currently some of these standards suggest the use of an ion chamber or similar radiation detection device to determine the testing radiation fields.

The testing of radiation detectors against these standards is mainly performed by determining the radiation fields of point sources or small extended sources. In order to produce the desired field, each testing laboratory might then position their radioactive source closer to or further from the detector, depending on the available source activity. Furthermore, the source encapsulation or container will affect the emission of the low energy $\mathrm{x}$-rays and gamma-rays, which in turn affects the measured or calculated exposure rate value at a fixed distance. In addition, instruments might not have a flat energy response for photons from $1 \mathrm{keV}$ to $3 \mathrm{MeV}$ and are principally calibrated only for ${ }^{137} \mathrm{Cs}$. In general, corrections must be made to instrument response before the devices can provide accurate readings for sources containing a different radionuclide species (i.e. more gamma lines with different energies than ${ }^{137} \mathrm{Cs}$ ). Furthermore,

${ }^{1}$ NIST does not endorse the use of non-SI units. This paper uses non-SI units because it addresses the requirements listed in the ANSI/IEEE published standards. 
testing of radiation detectors can be conducted in different laboratories located in different geographical locations with different levels of background radiation. These laboratories may also have different types of instruments or ways of calculating the exposure rate or ambient dose equivalent rate used for testing. The combined effect of all these differences becomes particularly problematic when they can influence the outcome of the radiation detector test, causing it to pass or fail a requirement listed in an ANSI/IEEE or IEC standard. Therefore, it is critical to have a consistent way of setting up the radiation fields so that the instruments can be tested in a fair and equitable manner. To accomplish this, we recommended that the source activity or source gamma-ray emission rate (for a specific gamma-ray line) and measurement distance be defined as the testing parameters in the ANSI/IEEE and IEC standards instead of making use of ambient dose equivalent rate or exposure rate.

In this work we provide results which illustrate the expected variation when determining the testing radiation fields using different calculation and measurement approaches. The large variations observed support our claim that better consistency in the test radiation fields can be achieved by specifying the source activity or source gamma-ray emission rate (for a specific gamma-ray line) and distance instead of the field strength.

\section{Measurements}

The gamma ambient dose equivalent rate and exposure rate were measured using the Victoreen 451PDE-SI-RYR ${ }^{2}$ (ambient dose equivalent rate), the Thermo FH40G-L (exposure rate), and the Ludlum 9DP (exposure rate), respectively. The measurements were performed in both the count rate and integration modes of the Victoreen 451P-DE-SI-RYR, the Thermo FH40G-L, and the Ludlum 9DP. The integration time was $300 \mathrm{~s}$. Ten independent readings were acquired, from which the mean and standard deviation were calculated for each radionuclide. The Victoreen 451P-DE-SI-RYR is a pressurized $230 \mathrm{~cm}^{3}$ volume air ionization chamber, pressurized to 6 atmospheres with a plastic casing. The Thermo FH40G-L has an internal proportional detector with a plastic casing. The Ludlum 9DP is a pressurized $230 \mathrm{~cm}^{3}$ volume air ionization chamber, pressurized to 8.5 atmospheres with a plastic casing.

The sources used for these measurements are listed in Table 2. Each source was encapsulated with $0.254 \mathrm{~mm}$ of stainless steel. The construction of these sources is described in detail in Refs. [1] and [2].

Table 2. Activities for gamma-ray and neutron sources

\begin{tabular}{|c|c|c|}
\hline Source & Activity (kBq) & Reference time \\
\hline${ }^{241} \mathrm{Am}$ & 1910 & $6 / 15 / 20056: 00$ AM EST \\
\hline${ }^{133} \mathrm{Ba}$ & 5480 & $6 / 15 / 20056: 00$ AM EST \\
\hline${ }^{60} \mathrm{Co}$ & 1660 & $7 / 11 / 201112: 00$ PM EST \\
\hline${ }^{137} \mathrm{Cs}$ & 3150 & $6 / 15 / 20016: 00$ AM EST \\
\hline${ }^{226} \mathrm{Ra}$ & 295 & $3 / 7 / 200512: 00$ PM EST \\
\hline${ }^{232} \mathrm{Th}$ & 550 & $3 / 1 / 200512: 00$ PM EST \\
\hline \multicolumn{2}{|c|}{} \\
\hline${ }^{232} \mathrm{U}$ & 501 & $8 / 1 / 200612: 00$ PM EST \\
\hline \multicolumn{2}{|c|}{ The uncertainty in the activities and neutron emission rate is 10\% $(1 \sigma)}$. \\
\hline
\end{tabular}

Measurements were performed with each source placed at a distance of $1 \mathrm{~m}$ from the reference point of the instrument. The sources were placed in a polymethyl methacrylate (PMMA) holder that provides no additional shielding to the source. The source holder is mounted on a track system that can set the sourceto-detector distance with a precision of $0.1 \mathrm{~mm}$. The track system is placed on a laboratory bench located in a low scatter room. The source center was placed at a height of approximately $60 \mathrm{~cm}$ from the top surface of the laboratory bench.

\footnotetext{
${ }^{2}$ Certain commercial equipment, instruments, or materials are identified in this paper to foster understanding. Such identification does not imply recommendation or endorsement by the National Institute of Standards and Technology, nor does it imply that the materials or equipment identified are necessarily the best available for the purpose.
} 
The calibration of the Victoreen 451P-DE-SI-RYR, the Thermo FH40G-L and the Ludlum 9DP was verified by using one of the National Institute of Standards and Technology (NIST) ${ }^{137}$ Cs calibration beams. The instrument readings were within $8 \%$ of the NIST delivered radiation field.

\section{Calculations}

Exposure rates for each radioactive source listed in Table 2 were calculated using two different methods: (1) Hand-calculation using a point-source approximation [3]; (2) Monte Carlo radiation transport simulation. Details about these two methods are described in the sections below. Both calculation methods used the same $\mathrm{x}$-ray and gamma-ray emission probabilities published by the Laboratoire National Henri Becquerel (LNHB) [7] and the Brookhaven National Laboratory Nuclear Data Center (BNL) [8].

The exposure rate calculations were performed first by assuming unshielded radionuclide point sources in air, and then by including the $0.254 \mathrm{~mm}$ stainless steel encapsulation. The bare source values were compared with the published values by Smith et al. [9] and with those obtained from the Rad Pro calculator [10]. For the bare sources, the exposure rate constants were also calculated as a function of the photon cutoff energy to demonstrate the sensitivity of this quantity to the choice of emission lines included in the calculations.

The ANSI/IEEE standards also specify masking or simultaneous radionuclide identification tests as a function of the ratios of the individual radionuclide exposure rates. In these tests sources such as ${ }^{131}$ I or ${ }^{99 \mathrm{~m}} \mathrm{Tc}$ (medical isotopes) are required to be shielded by $7.64 \mathrm{~cm}$ of PMMA to simulate attenuation by the human body. The exposure rates per unit activity for this scenario were calculated using both methods at a distance of $1 \mathrm{~m}$.

\section{Calculation Method 1: Point Source Approximation}

The point source approximation method is described in Ref. [3] and can be summarized as follows. The exposure rate constant expressed in units of $\mathrm{R} \mathrm{m}^{2} \mathrm{~h}^{-1} \mathrm{Ci}^{-1}$ for an isotope that emits one photon of energy $\mathrm{h} v$ per disintegration is approximated as:

$$
\Gamma_{\delta}=194.5 \mathrm{~h} v\left(\mu_{\mathrm{ab}} / \rho\right)_{\mathrm{air}}
$$

where $h v$ is the energy of the photon emitted expressed in $\mathrm{MeV}$ and $\left(\mu_{\mathrm{ab}} / \rho\right)_{\mathrm{air}}$ is the mass energy absorption coefficient for dry air expressed in $\mathrm{m}^{2} / \mathrm{kg}$ [4]. This equation assumes that the average energy required to cause one ionization in air is a constant equal to $33.85 \mathrm{~J} / \mathrm{C}$ ( $\mathrm{eV}$ per pair) and a cut-off energy of $\delta$. In this paper the exposure rate constant is expressed in units of $\mathrm{R} \mathrm{m}^{2} \mathrm{~h}^{-1} \mathrm{Ci}^{-1}$ (non-SI units) because all the ANSI/IEEE standards listed in Table 1 specify exposure rate in units of $\mathrm{R} \mathrm{h}^{-1}$ and activity in Ci (where $1 \mathrm{C} / \mathrm{kg}=3876 \mathrm{R}, 1 \mathrm{Ci}=3.7 \times 10^{10} \mathrm{~Bq}$ ).

The exposure rate constant for an isotope that emits photons $h v_{1}, h v_{2}, h v_{3} \ldots h v_{n}$ and the number of these per disintegration is $\mathrm{N}_{1}, \mathrm{~N}_{2}, \mathrm{~N}_{3} \ldots \mathrm{N}_{\mathrm{n}}$ can be approximated as:

$$
\Gamma_{\delta}=194.5 \sum_{i=1}^{n} N_{i} h v_{i}\left(\frac{\mu_{a b}^{i}}{\rho}\right)_{a i r} .
$$

The exposure rate, $\dot{X}$, at a distance $d$ from a point source with activity $A$ can then be expressed as:

$$
\dot{X}=\frac{\Gamma_{\delta} A}{d^{2}} .
$$

A narrow-beam of monoenergetic photons with an incident intensity $I_{0}$, penetrating a layer of material with thickness $x$ (expressed in $\mathrm{cm}$ ) and density $\rho$ (expressed in $\mathrm{g} / \mathrm{cm}^{3}$ ), emerges with an intensity $I$ given by an exponential attenuation law: 


$$
\frac{I}{I_{0}}=\exp [-(\mu / \rho) x \rho]
$$

where $\mu / \rho$ is the mass attenuation coefficient expressed in units of $\mathrm{cm}^{2} / \mathrm{g}$ [4]. Then for a shielded source the exposure rate can be approximated as:

$$
\dot{X}=\frac{A 194.5 \sum_{i=1}^{n} N_{i} h v_{i}\left(\frac{\mu_{a b}^{i}}{\rho}\right)_{\text {air }} \exp \left[-(\mu / \rho)_{i} x \rho\right]}{d^{2}} .
$$

\section{Calculation Method 2: Monte Carlo Radiation Transport}

Monte Carlo radiation transport calculations were performed using the Monte Carlo N-Particle eXtended code version 2.5.0 (MCNPX) [5]. Each radionuclide source was modeled as a point source in air emitting photons with the appropriate energies and relative emission probabilities. MCNPX's F6 tally was used to obtain a track-length estimate of the collision kerma in a $1 \mathrm{~cm}$ thick spherical shell of air of radius $1 \mathrm{~m}$ which was concentric with the source. The tally result (expressed in units of $\mathrm{MeV} / \mathrm{g} / \mathrm{photon}$ emitted) was then converted to exposure rate at $1 \mathrm{~m}$ per unit activity of the source (expressed in $\mathrm{R} \mathrm{h}^{-1} \mathrm{Ci}^{-1}$ ) through the equation:

$$
\frac{\dot{X}}{\mathrm{~A}}=2.4436 \times 10^{6} \cdot T N_{\text {total }}
$$

where T is the MCNPX F6 tally result and $N_{\text {total }}$ is the total number of photons emitted per disintegration, which is calculated for each radionuclide as:

$$
N_{\text {total }}=\sum_{i=1}^{n} N_{i}
$$

Like the hand-calculation method described above, this equation assumes $33.85 \mathrm{~J} / \mathrm{C}$ of charge released in air. The Monte Carlo simulations were performed in coupled photon-electron transport mode (mode p e) with the cutoff energies for both particle types set to the default value of $1 \mathrm{keV}$. MCNPX's standard physics models were employed with their default settings and included photoelectric absorption, coherent and incoherent scattering, pair production, fluorescence, and bremsstrahlung generation (from electrons liberated by photon interactions). The photon and electron cross-sections were taken from the default MCLIB04 [6] and ELO3 tables, respectively. The stainless steel and PMMA shielding in the MCNPX simulations were modeled as a sphere of the given radius centered at the point source. One hundred million particle histories were simulated to ensure that the relative Monte Carlo statistical uncertainties were in all cases smaller than $0.1 \%$.

\section{Results and Discussion}

The calculated exposure rate constants, $\Gamma_{\delta}$, for several bare radionuclides of interest for ANSI/IEEE standards testing are summarized in Table 3 together with the values obtained from Refs. [9] and [10]. The point source calculations are given for two cut-off energies, $1 \mathrm{keV}$ and $40 \mathrm{keV}$. MCNPX results are shown for two different decay data libraries from which the emission probabilities for all x-rays and gamma-rays with energies greater than $1 \mathrm{keV}$ were extracted. 
Table 3. Summary of calculated exposure rate constants for bare sources

\begin{tabular}{|c|c|c|c|c|c|c|}
\hline \multirow[b]{2}{*}{ Source } & \multicolumn{6}{|c|}{ Exposure rate constant $\left(\mathrm{R} \mathrm{m}^{2} \mathrm{~h}^{-1} \mathrm{Ci}^{-1}\right)$} \\
\hline & $\begin{array}{c}\text { Point source } \\
\text { method } \\
(1 \mathrm{keV})\end{array}$ & $\begin{array}{c}\text { Point source } \\
\text { method } \\
(40 \mathrm{keV})\end{array}$ & $\begin{array}{l}\text { MCNPX } \\
\text { method } \\
\text { (LNHB) }\end{array}$ & $\begin{array}{l}\text { MCNPX } \\
\text { method } \\
\text { (NBL) }\end{array}$ & $\begin{array}{c}\text { Smith et al. } \\
\text { [9] }\end{array}$ & $\begin{array}{c}\text { Rad Pro } \\
\text { Calculator } \\
\text { [10] }\end{array}$ \\
\hline${ }^{241} \mathrm{Am}$ & 0.0925 & 0.0155 & 0.1189 & 0.0970 & 0.0749 & 0.0166 \\
\hline${ }^{133} \mathrm{Ba}$ & 0.2941 & 0.1948 & 0.3045 & 0.3060 & 0.3041 & 0.1993 \\
\hline${ }^{60} \mathrm{Co}$ & 1.2942 & 1.2942 & 1.2956 & 1.2964 & 1.2907 & 1.2926 \\
\hline${ }^{137} \mathrm{Cs}$ & 0.3574 & 0.3523 & 0.3263 & 0.3269 & 0.3428 & 0.3211 \\
\hline${ }^{131} \mathrm{I}$ & 0.2169 & 0.2125 & 0.2210 & 0.2212 & 0.2199 & 0.2035 \\
\hline${ }^{40} \mathrm{~K}$ & 0.0733 & 0.0733 & 0.0769 & 0.0802 & 0.0780 & 0.0779 \\
\hline${ }^{226} \mathrm{Ra}$ & 0.9415 & 0.7787 & 1.0410 & 0.8971 & 0.0039 & 0.7331 \\
\hline${ }^{99 \mathrm{~m}} \mathrm{Tc}$ & 0.0672 & 0.0515 & 0.0777 & 0.0773 & 0.0795 & 0.0777 \\
\hline${ }^{232} \mathrm{Th}$ & 1.4386 & 1.1280 & 1.4811 & 1.1504 & 0.0144 & 0.0001 \\
\hline${ }^{232} \mathrm{U}$ & 0.6855 & 0.6855 & - & 0.7012 & 0.0234 & 0.0066 \\
\hline
\end{tabular}

In Table 3 the MCNPX and the point source method calculations for ${ }^{226} \mathrm{Ra},{ }^{232} \mathrm{Th}$ and ${ }^{232} \mathrm{U}$ include the entire decay chain and assume that the ${ }^{226} \mathrm{Ra}$ and ${ }^{232} \mathrm{Th}$ sources are in equilibrium, and that the ${ }^{232} \mathrm{U}$ source is 15 years old. The values for these radionuclides listed in Smith et al. [9] do not include the progeny. However, Smith et al. [9] did combine decay schemes for those radionuclides which do not have photon emissions themselves, but which are in secular equilibrium with photon-emitting products (e.g. ${ }^{137} \mathrm{Cs} /{ }^{137 \mathrm{~m}} \mathrm{Ba}$ ). Smith et al. [9] used a cut-off energy of $15 \mathrm{keV}$ and included all photons with emission probabilities greater than $0.01 \%$. Their calculations also neglected bremsstrahlung, assumed $34 \mathrm{eV}$ per ion pair created in air, and the mass-energy absorption coefficients for air were obtained from [4]. On the other hand, the Rad Pro calculator included the entire decay chain for ${ }^{226} \mathrm{Ra}$, but not for ${ }^{232} \mathrm{Th}$ or ${ }^{232} \mathrm{U}$. The Rad Pro Calculator assumes that the average amount of energy required to produce an ionization event in air is $33.8 \mathrm{eV}$ per ion pair and restricts the calculations to photons with emission probabilities greater than $1 \%$.

From Table 3 it can be observed that the exposure rate constants differ depending on the photon emission probabilities, the cut-off energy, the mass-energy absorption coefficients, and the selected value for the average energy required to cause one ionization in air. The mass-energy absorption coefficients will depend not only on the choice of the atomic cross-section library, but also on the method used to interpolate the tabulated data to obtain values at the required photon energies. The calculated exposure rate constants display a variation between $1 \%$ and $20 \%$, but for several radionuclides the variation was $50 \%$ or larger.

The background subtracted exposure rate values measured for the sources listed in Table 2 using the Victoreen 451P-DE-SI-RYR, the Thermo FH40G-L, and the Ludlum 9DP are summarized in Table 4. For comparison purposes these values are listed together with the corresponding calculated values using the point source approximation (with a cut-off energy of $40 \mathrm{keV}$ ) and MCNPX method (using the LNHB decay library). The calculated values account for the $0.254 \mathrm{~mm}$ thick stainless steel source encapsulation. The ambient radiation background measured by the Victoreen 451P-DE-SI-RYR was $(0.046 \pm 0.027) \mu \mathrm{Sv} / \mathrm{h}$ when measured in the rate mode and $(0 \pm 0.05) \mu \mathrm{Sv} / \mathrm{h}$ when measured in the integration mode (300 s integration time). The ambient radiation background measured by the Thermo FH40G-L was ( $8.61 \pm 0.37)$ $\mu R / h$ when measured in the rate mode and $(10.4 \pm 0.5) \mu R / h$ when measured in the integration mode. The ambient radiation background measured by the Ludlum 9DP was $(8.78 \pm 1.61) \mu R / h$ when measured in the rate mode. 
Table 4. Measured and calculated exposure rate values at $1 \mathrm{~m}$ for different encapsulated sources

\begin{tabular}{|c|c|c|c|c|c|c|c|c|}
\hline \multirow{3}{*}{ Source } & \multicolumn{6}{|c|}{ Measured values at $1 \mathrm{~m}$} & \multicolumn{2}{|c|}{ Calculated values at $1 \mathrm{~m}$} \\
\hline & \multicolumn{2}{|c|}{$\begin{array}{c}\text { Victoreen 451P-DE-SI-RYR } \\
(\mu \mathrm{Sv} / \mathrm{h})\end{array}$} & \multicolumn{2}{|c|}{$\begin{array}{c}\text { Thermo FH40G-L } \\
(\mu R / h)\end{array}$} & \multicolumn{2}{|c|}{$\begin{array}{c}\text { Ludlum 9DP } \\
(\mu \mathrm{R} / \mathrm{h})\end{array}$} & \multirow{2}{*}{$\begin{array}{c}\text { Point } \\
\text { source } \\
\text { method } \\
(40 \mathrm{keV}) \\
(\mu \mathrm{R} / \mathrm{h})\end{array}$} & \multirow{2}{*}{$\begin{array}{c}\text { MCNPX } \\
\text { method } \\
(\mathrm{LNHB}) \\
(\mu \mathrm{R} / \mathrm{h})\end{array}$} \\
\hline & Rate & Integration & Rate & Integration & Rate & Integration & & \\
\hline${ }^{241} \mathrm{Am}$ & $0.014 \pm 0.027$ & $0 \pm 0.05$ & $0.73 \pm 0.09$ & $1.15 \pm 0.38$ & $2.78 \pm 0.36$ & $1.26 \pm 0.25$ & 0.626 & 0.560 \\
\hline${ }^{133} \mathrm{Ba}$ & $0.261 \pm 0.038$ & $0.12 \pm 0.05$ & $31.7 \pm 3.6$ & $20.1 \pm 2.4$ & $20.9 \pm 1.2$ & $21.1 \pm 0.8$ & 13.6 & 20.1 \\
\hline${ }^{60} \mathrm{Co}$ & $0.506 \pm 0.062$ & $0.51 \pm 0.06$ & $65.3 \pm 5.8$ & $63.9 \pm 5$ & $48.1 \pm 5.2$ & $46.9 \pm 1.8$ & 47.6 & 47.5 \\
\hline${ }^{137} \mathrm{Cs}$ & $0.284 \pm 0.050$ & $0.24 \pm 0.05$ & $29.5 \pm 2.4$ & $27.4 \pm 3.2$ & $24.0 \pm 2.9$ & $24.2 \pm 2.8$ & 25.2 & 22.9 \\
\hline${ }^{226} \mathrm{Ra}$ & $0.089 \pm 0.033$ & $0.074 \pm 0.037$ & $5.53 \pm 1.78$ & $9.29 \pm 1.89$ & $6.37 \pm 0.45$ & $5.82 \pm 0.73$ & 6.10 & 7.01 \\
\hline${ }^{232} \mathrm{Th}$ & $0.131 \pm 0.047$ & $0.098 \pm 0.051$ & $25.7 \pm 1.9$ & $22.1 \pm 1.8$ & $11.3 \pm 1.5$ & $14.5 \pm 1.5$ & 16.9 & 17.2 \\
\hline${ }^{232} \mathrm{U}$ & $0.104 \pm 0.030$ & $0.12 \pm 0.05$ & $15.3 \pm 1.6$ & $14.3 \pm 1.8$ & $9.38 \pm 1.82$ & $7.98 \pm 0.68$ & 9.15 & 9.43 \\
\hline
\end{tabular}

The reported uncertainties for the measurements are equal to the standard deviation of 10 readings with a coverage factor of $\mathrm{k}=2$. From Table 4 it can be observed that the ${ }^{137} \mathrm{Cs}$ measurements, in the rate and integration mode for Victoreen 451P-DE-SI-RYR, Thermo FH40G-L and Ludlum 9DP detectors, agree within the uncertainty values, while the calculated values are within $30 \%$ of the measured values. For all other radionuclides the variations between the measured and calculated values are much larger than the measured uncertainties. Except for ${ }^{226} \mathrm{Ra}$, the Victoreen 451P-DE-SI-RYR readings are always lower than those of the Thermo FH40G-L instrument. The differences in the exposure rate measurements from the calculations for ${ }^{60} \mathrm{Co}$ are higher by approximately a factor of 5 . Longer integration times for the Victoreen 451P-DE-SI-RYR are required to obtain more accurate measurements.

Source shielding adds an additional variable to the determination of the exposure rate values for the masking and target sources used for testing. Calculated values will depend on the choice of mass attenuation coefficients used to account for the source encapsulation. The calculated values for ${ }^{131} \mathrm{I}$ and ${ }^{99 \mathrm{~m}}$ Tc point sources surrounded by $7.64 \mathrm{~cm}$ of PMMA are shown in Table 5. The calculations assumed a PMMA density of $1.19 \mathrm{~g} / \mathrm{cm}^{3}$ and the mass attenuation coefficients were extracted from [4]. The exposure rate constants calculated using MCNPX are approximately 2 times larger for ${ }^{131} \mathrm{I}$ and 3.5 times larger for ${ }^{99 \mathrm{~m}} \mathrm{Tc}$ than the corresponding values obtained using the point source method. This is because the MCNPX method includes contributions from Compton scattered photons, while the point source method does not.

Table 5. Summary of calculated exposure rate constants for shielded sources

\begin{tabular}{|c|c|c|c|c|}
\hline \multirow{2}{*}{ Source } & \multicolumn{4}{|c|}{ Exposure rate constant $\left(\mathbf{R ~ m}^{\mathbf{2}} \mathbf{h}^{-\mathbf{1}} \mathbf{C i}^{\mathbf{- 1}}\right)$} \\
\cline { 2 - 5 } & $\begin{array}{c}\text { Point source } \\
\text { method (1 keV) }\end{array}$ & $\begin{array}{c}\text { Point source } \\
\text { method (40 keV) }\end{array}$ & $\begin{array}{c}\text { MCNPX method } \\
(\mathbf{L N H B})\end{array}$ & $\begin{array}{c}\text { MCNPX method } \\
\text { (NBL) }\end{array}$ \\
\hline${ }^{131} \mathrm{I}$ & 0.0819 & 0.0817 & 0.1550 & 0.1554 \\
\hline${ }^{99 \mathrm{~m}} \mathrm{Tc}$ & 0.0135 & 0.0134 & 0.0455 & 0.0457 \\
\hline
\end{tabular}

In order to obtain an estimate of the instrument behavior when measuring shielded sources, the ${ }^{133} \mathrm{Ba}$ source from Table 2 and a ${ }^{57}$ Co source (Activity $=1.76 \mathrm{MBq}( \pm 10 \%, k=1)$, reference time $=9 / 1 / 12$ 12:00 PM EST) with the same type of encapsulation were shielded by placing them inside a PMMA container with a $9 \mathrm{~cm}$ wall thickness. The measurements and calculated exposure rate values are listed in Table 6 . Measurements were performed at $0.2 \mathrm{~m}$ and $1 \mathrm{~m}$. The ${ }^{57} \mathrm{Co}$ and ${ }^{133} \mathrm{Ba}$ sources were used instead of the ${ }^{99 \mathrm{~m}} \mathrm{Tc}$ and ${ }^{131} \mathrm{I}$ because of their longer half-life and the similarity in their emitted gamma-ray energies. 
Table 6. Measured exposure rate values for shielded sources

\begin{tabular}{|c|c|c|c|c|c|c|}
\hline \multirow{3}{*}{ Source } & \multicolumn{6}{|c|}{ Exposure rate and ambient dose equivalent rate values } \\
\hline & \multicolumn{2}{|c|}{$\begin{array}{c}\text { Victoreen 451P-DE-SI-RYR } \\
(\mu \mathrm{Sv} / \mathrm{h})\end{array}$} & \multicolumn{2}{|c|}{$\begin{array}{c}\text { Thermo FH40G-L } \\
(\mu \mathrm{R} / \mathrm{h})\end{array}$} & \multicolumn{2}{|c|}{$\begin{array}{c}\text { Point source method }(40 \mathrm{keV}) \\
(\mu \mathrm{R} / \mathrm{h})\end{array}$} \\
\hline & at $0.2 \mathrm{~m}$ & at $1 \mathrm{~m}$ & at $0.2 \mathrm{~m}$ & at $1 \mathrm{~m}$ & at $0.2 \mathrm{~m}$ & at $1 \mathrm{~m}$ \\
\hline${ }^{133} \mathrm{Ba}$ & $5.0 \pm 0.6$ & $0.144 \pm 0.06$ & $387 \pm 98$ & $8 \pm 1$ & 123 & 4.93 \\
\hline${ }^{57} \mathrm{Co}$ & $0.57 \pm 0.10$ & $0.002 \pm 0.001$ & $43 \pm 6$ & $0.55 \pm 0.04$ & 8.1 & 0.32 \\
\hline
\end{tabular}

For the ${ }^{57}$ Co source at $1 \mathrm{~m}$ from the detector, the readings were close to background levels, explaining the large variations observed in the measured values seen in Table 6 . The measurements at $0.2 \mathrm{~m}$ agree within the measured uncertainties, given with a coverage factor of $k=2$ (calculated as described for Table 4). The measured values at $0.2 \mathrm{~m}$ are approximately between 3 to 7 times larger than the calculated values using the point source method that does not account for Compton scattered photons. The data clearly demonstrate that the Compton scattered photons contribute significantly to the measured exposure rate or ambient dose equivalent rate in this source-detector geometry. Appropriate conversion factors should be applied to the measured ambient dose equivalent rates in order to compare them to calculated exposure rate values. ISO 4037-3 [11] provides a list of conversion factors for mono-energetic parallel photon beams that could be used to perform these calculations.

Lastly, the exposure rate constants were calculated for each radionuclide as a function of the photon cut-off energy using the point source approximation. Figure 1 shows that calculated exposure rate constants for some radionuclides, such as ${ }^{131} \mathrm{I}$, are fairly insensitive to the choice of cut-off energy. However, the values for other radionuclides, such as ${ }^{133} \mathrm{Ba}$, show a much greater dependence. For instance, the exposure rate constant for ${ }^{133} \mathrm{Ba}$ increases by more than $30 \%$ when photons with energies less than $36 \mathrm{keV}$ are included in the calculation. This result explains the variation in exposure rate measured by different detectors, the fundamental parameter being the thickness of the detector casing or sensitive window which determines the lowest photon energy that the instrument can measure.

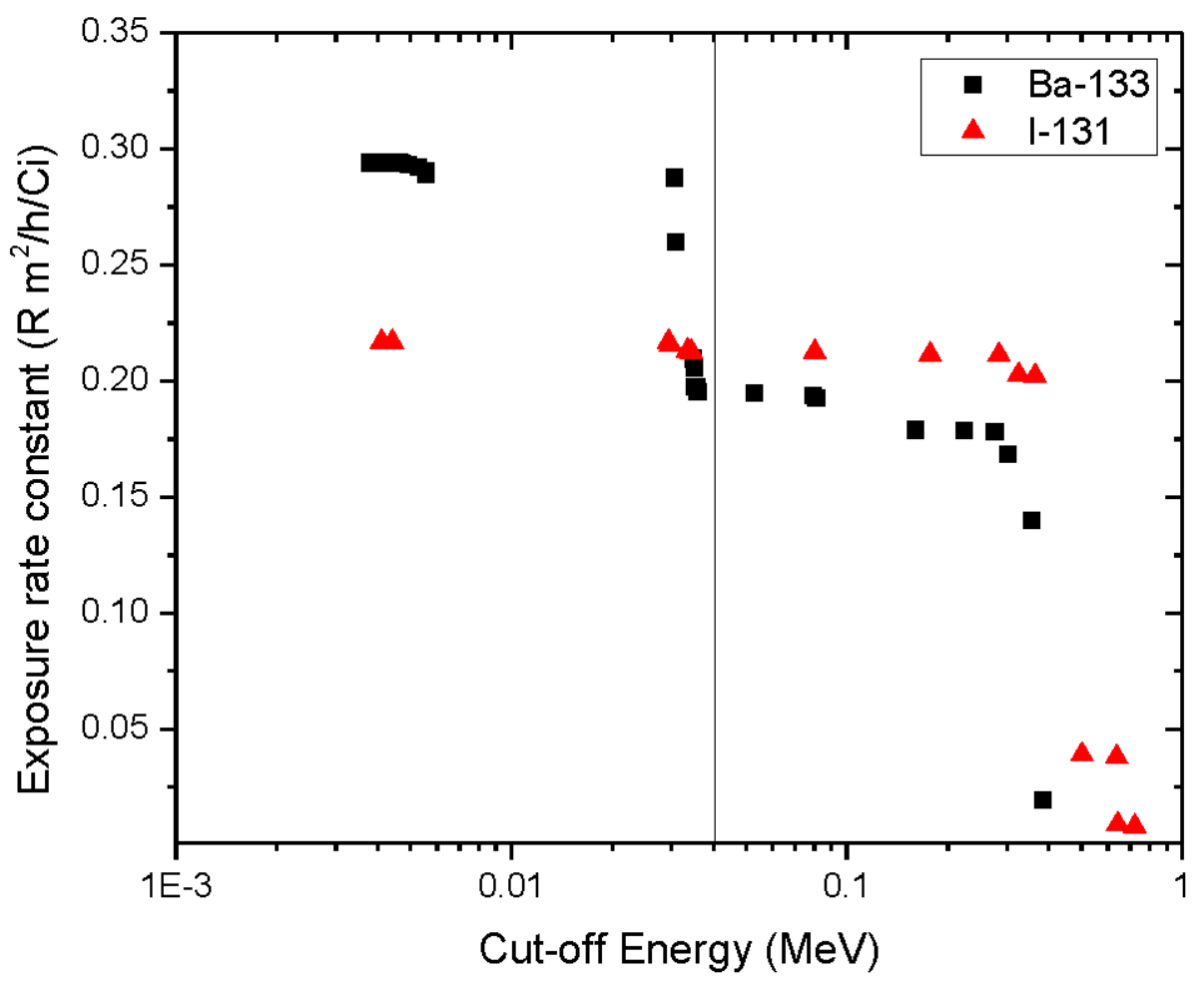

Fig. 1. Calculated exposure rate constant as a function of cut-off energy for ${ }^{131} \mathrm{I}$ and ${ }^{133} \mathrm{Ba}$. 


\section{Conclusions}

The determination of the exposure rate values for testing radiation detection instruments against the ANSI/IEEE standards widely depends on the method used to determine the radiation field. As testing can occur in different laboratories, which may use different methods to determine the testing radiation field, the observed response of the instruments under test can be very different from laboratory to laboratory. These differences could cause an instrument to erroneously pass or fail an ANSI/IEEE test requirement depending on the laboratory that performs the testing. It is our recommendation that the ANSI/IEEE as well as the IEC standards define the test conditions using source activity or gamma-ray emission rate (for specific gammaray lines) instead of exposure rate or ambient dose equivalent rate values. This approach would help improve consistency in the fields used to evaluate radiation detectors across the various testing laboratories. Specifying the source activity or gamma-ray emission rates (for specific gamma-ray lines) with the associated allowed testing range ( $\pm 20 \%$ from nominal activity value) has two key advantages: (1) the uncertainty in the measurement is known; and (2) the instrument manufacturers know exactly the lowest activity range for which their instrument needs to be designed to detect and/or identify a given isotope. In contrast, if the test fields are specified in the standards in terms of exposure and ambient dose equivalent rates, then the actual fields produced at the various testing laboratories might vary by orders of magnitude depending on the tools they use to determine them (measurements or calculations).

\section{Acknowledgments}

The authors would like to thank the Department of Homeland Security (DHS) Domestic Nuclear Detection Office (DNDO) for funding this work. Mr. Mille was funded by a graduate fellowship from the DOE Office of Nuclear Energy's Nuclear Energy University Programs. The authors would also like to thank Dr. Ronaldo Minniti from NIST for doing the instrument calibration measurements.

\section{References}

[1] L. Lucas, L. Pibida, M. Unterweger, and L. Karam, Gamma-ray Emitting Test Sources for Portal Monitors Used for Homeland Security, Radiation Protection Dosimetry, Vol. 113, No. 1, pp. 108-111 (2005).

[2] L. Pibida, M. Unterweger, L. Karam. Development of gamma-ray emitting test sources for portal monitors, Applied Radiation and Isotopes, Vol. 64, pp. 1271-1272 (2006).

[3] The physics of radiology, $4^{\text {th }}$ Edition, Publisher Charles C. Thomas. Authors: Harold Elford Johns and John Robert Cunningham.

[4] J. H. Hubbell and S. M. Seltzer. Tables of x-ray mass attenuation coefficients and mass energy-absorption coefficients $1 \mathrm{keV}$ to $20 \mathrm{MeV}$ for elements $\mathrm{Z}=1$ to 92 and 48 additional substances of dosimetric interest. NISTIR 5632. May 2005. http://www.nist.gov/pml/data/xraycoef/index.cfm

[5] D. B. Pelowitz, ed., MCNPX User's Manual, Version 2.5.0, Los Alamos National Laboratory report LA-CP-05-0369 (April 2005).

[6] M. C. White, 2002 Photoatomic Data Library MCPLIB04: A New Photoatomic Library Based on Data from ENDF/B-VI Release 8, Los Alamos National Laboratory Internal Memorandum X-5: MCW-02-111 and LA-UR-03-1019.

[7] Laboratoire National Henri Becquerel (LNHB), Recommended Data, http://www.nucleide.org/DDEP_WG/DDEPdata.htm.

[8] Nuclear Data Center, Brookhaven National Laboratory, Evaluated Nuclear Structure Data File (ENSDF), http://www.nndc.bnl.gov/.

[9] D. S. Smith and M. G. Stabin. Exposure Rate Constants and Lead Shielding values for over 1,100 Radionuclides, Health Physics The Radiation Safety Journal, Vol. 102, No. 3, pp. 271-291, March 2012.

[10] Rad Pro Calculator http://www.radprocalculator.com/Gamma.aspx.

[11] ISO 4037-3, $\mathrm{X}$ and gamma reference radiation for calibrating dosemeters and doserate meters and for determining their response as a function of photon energy -- Part 3: Calibration of area and personal dosemeters and the measurement of their response as a function of energy and angle of incidence.

About the author: Leticia Pibida Field is a research physicist in the Ionizing Radiation Division of the NIST Physics Laboratory. The National Institute of Standards and Technology is an agency of the U.S. Department of Commerce. 